\title{
Analysis of the obligations for the assessment of the health risks related to the hygiene of air conditioning systems in indoor workplaces, with reference to the Risk Assessment Docu- ment (DVR) and to the microclimate conditions
}

\author{
Jacques Gandini ${ }^{1 *}$ \\ ${ }^{1}$ GANDINI S.R.L., managing Director, Renewable Energies in HVAC \& nearly Zero En- \\ ergy Buildings Consulting - 37045 Legnago, Verona, Italy
}

\begin{abstract}
Safety in the workplace has been regulated for years in Italy in a very complete manner and very often it is identified as a set of rules governed by the Legislative Decree of 9 April 2008, n. 81: Consolidated text on health and safety at work, implementation of article 1 of the law of 3 August 2007, no. 123 regarding the protection of health and safety in the workplace. Very often, within the Risk Assessment Document (DVRDocumento di Valutazione dei Rischi), required by law for all companies that have at least one worker, the risks associated with air conditioning and ventilation systems are not always sufficiently taken into consideration, as regards to workers safety at workplace. Numerous studies have shown that microbiological and chemical contamination of the air in confined indoor spaces inside buildings can be attributable to poor hygienic conditions, overcrowding of the premises and/or situations where it is not possible to ensure proper cleaning and maintenance of the aeraulic systems themselves. In this context, this research provides an interesting analysis of some of the main problems inherent in the maintenance of aeraulic systems and their implications, for the parties involved by law, in terms of non-compliance with the provisions of Legislative Decree 9 April 2008, no.81, offering useful ideas for those who want to ensure maximum energy efficiency and healthiness of air conditioning and/or ventilation systems. Keywords: indoor air quality (IAQ), indoor environmental quality (IEQ), air cleaning, air purification, air disinfection, mechanical ventilation, nearly Zero Energy Buildings (nZEB), Renovation Wave EU.
\end{abstract}

\section{Introduction}

The European Commission in the last 15 years matured a strong commitment to sustainable development as an indispensable element to guarantee economic prosperity and life quality for people respecting the planet. For these reasons, with particular attention to buildings, that are responsible, directly or indirectly, for almost $40 \%$ of total primary energy consumption, the European Commission published, on October $14^{\text {th }} 2020$, "A Renovation Wave for Europe - Greening our buildings, creating jobs, improving lives" (COM(2020)662) a new strategy to boost the action in this sense. This strategy aims to double the annual energy renovation rates in the next ten years. These renovations will enhance, in the EU plan, the

\footnotetext{
* Corresponding author: j.gandini@gandinistudio.com
} 
quality of life for people living in and using buildings, reduce Europe's greenhouse gas emissions, and create up to 160,000 additional green jobs in the construction sector. With nearly 34 million Europeans unable to afford keeping their home adequately heated, renovation is also an important response to energy poverty. It can address the health and wellbeing of vulnerable people while reducing their energy bills, as outlined in the Commission Recommendation on Energy Poverty ((EU) 2020/1563), which was published as part of the Renovation wave strategy. In parallel to this strategy, the European Commission adopted new rules for the smart readiness of buildings (EU Document C(2020)6929-6930 - Detailing the technical modalities for the effective implementation of an optional common Union scheme for rating the smart readiness of buildings). Specifically, the smart readiness indicator aims to promote digitally friendly renovations, integrate renewable energy and enable measurements of actual energy consumption. All this will allow further increase in energy savings in the building sector, with a special focus on building intelligent use.

The "Renovation Wave for Europe" initiative will be based on measures taken with the Clean energy for all Europeans package, notably the requirement for each EU country to publish a long-term building renovation strategy (LTRS), other aspects of the amending Directive on the Energy Performance of Buildings (so called EPBD - (EU) 2018/844), and building-related aspects of each EU country's national energy and climate plans (NECP).

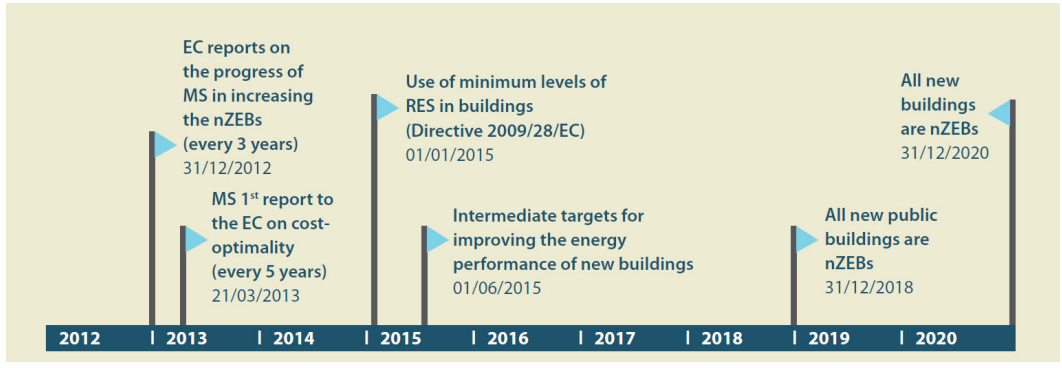

Fig. 1 - Key years for nearly Zero-Energy Buildings (Directive 2010/31/EC), Source: Buildings Performance Institute Europe (BPIE)

This wave of renovation in the building sector, in line with the provisions of the European Directive (EU) 2018/844 on energy efficiency in buildings as a recast of the previous Directive 2010/31/EU (the so-called EPBD, Energy Performance of Buildings Directive), both in the public and in the private sector and in new buildings and existing ones, is possible thanks to the use of highly insulating materials, energy efficient HVAC plant solutions and cutting-edge construction techniques, which ensure that the energy needs of the new buildings tends to be lower and lower, using huge quantities of renewable energy, with obligations already active at EU-27 level, based on the following deadlines:

- 01/01/2019: new buildings owned by the public or occupied by public administrations must be $n Z E B$;

- 01/01/2021: all other new buildings (practically all private buildings) must be nZEB.

In these very efficient buildings, with very well insulated building envelope, a considerable part of the winter energy needs can be satisfied by the free heat inputs that allow energy savings for air conditioning during the cold months.

On the other hand, these free heat inputs can become disadvantageous in the summer season, since the high insulation of the building envelope contrasts their dissipation towards the outside. 
For this reason, substantial increases are expected in the world of intelligent shading (to limit the direct solar component in summer) and considering the fact that these buildings (as a side effect of a high degree of building envelop insulation) are increasingly hermetic, they are already requiring additional ventilation rates for confined spaces (e.g. meeting rooms, offices, schools but also places of everyday life such as private homes, etc.), since buildings so hermetic tend, by their nature, to imprison pollutants of the air (both internal and external to the building) and to favour the accumulation of excessive levels of $\mathrm{CO}_{2}$ and/or humidity and/or VOC inside the building occupied by people. In all these cases the correct use of ventilation is extremely important.

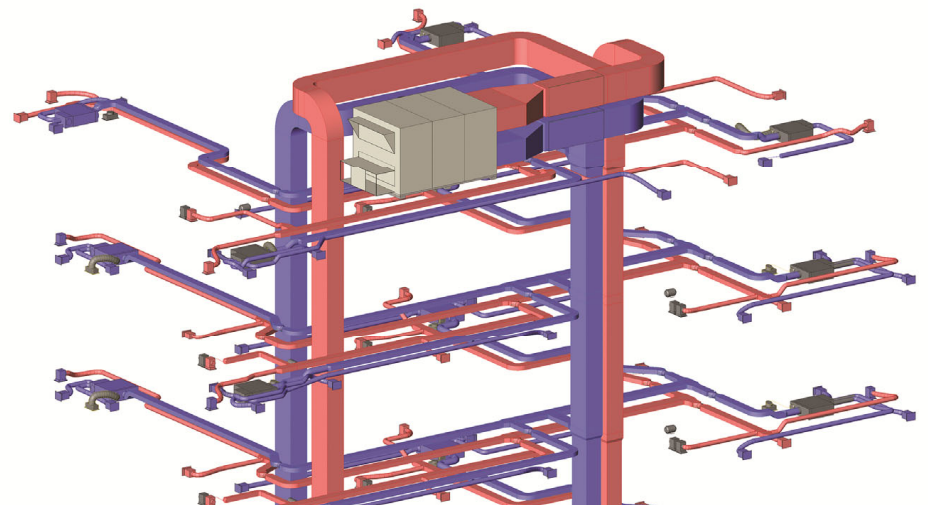

Fig. 2: Example image of a dual flow Mechanical Ventilation System with Centralized heat recovery unit and aeraulic network with local air distribution boxes for the different sections of the building

\section{The increasing use of ventilation systems in buildings}

The dilution technique is very often carried out in order to prevent the accumulation of pollutants inside buildings. This technique involves providing adequate ventilation to the indoor ambient of the building using outdoor purified air to replace indoor polluted air. It is preferable to use heat recovery systems, with devices and equipment of various nature and complexity that are often placed in the general field of HVAC such as climatization, air conditioning and ventilation systems, as defined by the UNI 10339:

- Climatization: Simultaneous implementation and maintenance in the rooms of the thermal, hygrometric, air quality and air movement conditions within the limits required for the well-being and comfort for people;

- Air conditioning: Treatment aimed at achieving the quality of the air and the thermal and hygrometric characteristics required;

- Ventilation: Realization and maintenance in the rooms of the above mentioned conditions. See definition of "Climatization", excluding thermal and hygrometric control.

In the decade 2020-2030 and then up to 2050, a great development is expected of these systems that use "air vector" to provide comfort and ventilation because, especially in the context of efficient buildings, now mandatory throughout the EU-27 territory, as required by the European Directive (EU) 2018/844, the use of "all year round" climatization, air conditioning and ventilation systems is increasingly required, both in guaranteeing the correct air renewal and purification and to allow, at the same time, through suitable heat recovery systems, energy saving as well as a massive use of renewable energy sources. 


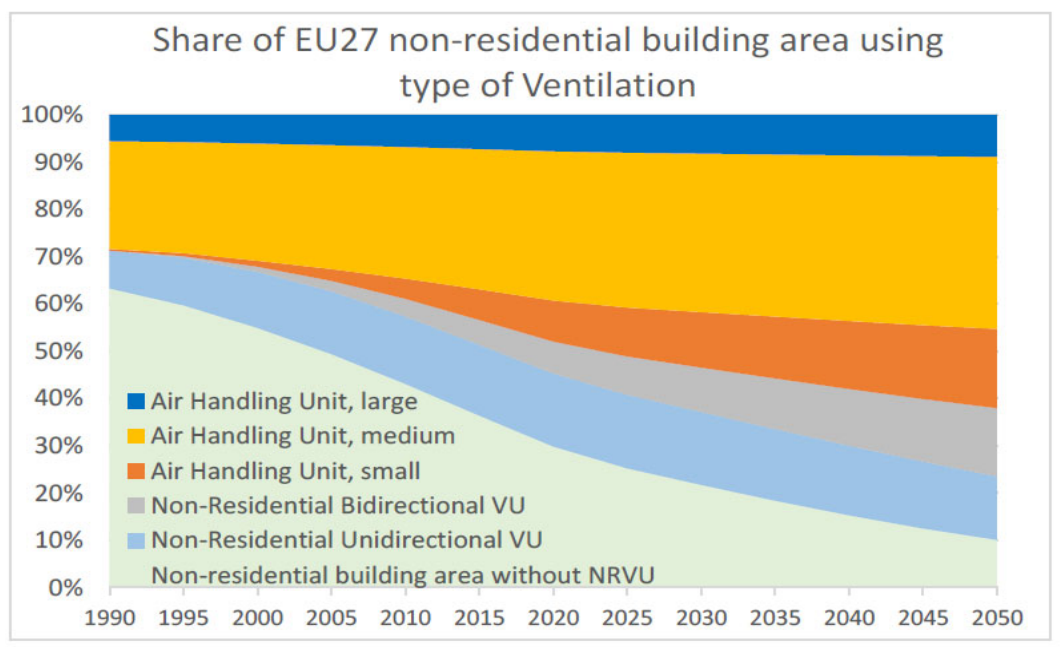

Fig. 3: Review study on Regulations EU 1253/2014 (Ecodesign requirements for ventilation units) and EU 1254/2014 (Energy labelling of residential ventilation units) of the European Commission September 2020

In particular, in non-residential buildings, for example where people work, the expected growing trend is very important. It is estimated that, considering $100 \%$ the total indoor square surface of non-residential buildings stock, the share of non-residential buildings with "at least one type of ventilation system" is already approximately $70 \%$ (reference year 2020 ) but it will shift to approximately $90 \%$ in 2050 , when the European Commission plans to become substantially carbon neutral.

With such large volumes and increases of ventilation systems adoption, it is extremely important to assure to building users that the cleanliness and hygiene standards of the new (or renewed) ventilation systems is firmly guaranteed from HVAC plants producers and installers, in particular at the moment of delivery of the building to the users. On the other hand, it is also extremely important to understand that the initial condition of cleanliness and hygiene of any ventilation systems, can weaken easily and drastically in a just a few months or years. In particular this can happen if during the life cycle of the ventilation system, planned activities of maintenance are not properly or correctly executed.

In such circumstances, e.g., in absence (or improper) maintenance of the ventilation systems, materials in the ventilation units or in the air ducts can degrade affecting negatively the quality of the air supplied to the indoor spaces and consequently generating several risks for the occupants and the workers inside those buildings by affecting the microclimate conditions to which they are exposed.

\section{Risks related to microclimatic conditions for human health in indoor workplace}

Before starting to assess the health risks for workers deriving from inadequate microclimate inside buildings, it is extremely important to underline that this condition (inadequate microclimate) is not always only attributable to the quality and maintenance of air condition- 
ing and ventilation systems but can also depend on various other factors related to the uses of buildings.

A microclimate that is risky for the health of workers may depend on excessive crowding in the workplace; for example, environments where many people work at the same time (such as call centers or large open spaces offices). If the access and the use of the spaces are not properly controlled in a manner that is commensurate with the capacity of the building and the sizing of the air renewal and purification systems, Workers are potentially exposed both to direct risks of a microclimatic nature (inadequate fresh air volumes and therefore an excess of $\mathrm{CO}_{2}$ ) and to indirect risks of a more subjective and psychological nature, such as crowding stress, feeling of lack of air as well as a concrete "biological risk" from interpersonal transmission of viruses and diseases and "physical risk" from noise.

Furthermore, it should not be underestimated that microclimate is a subjective component linked to the "physical risk" and to tensions and discontent often triggered by the different perception of the environmental condition (e.g. the level of the temperature perceived by the individual people may also depend on the different type of clothing and on the individual metabolism), it can generate disagreements on the thermal management of the office that can degenerate into another type of "physical risk" correlated with psychosomatic disorders and work discomforts which, although not directly connected to the microclimate and even less to the quality and hygiene of the ventilation systems, are an evident and significant consequence.

Having made this necessary premise, below is represented a possible interpretation of the three types of "physical, chemical and biological" risks that can be connected to the improper use and management of climatization, air conditioning and ventilation systems for the purpose of the realization of the DVR (Documento di Valutazione dei Rischi - Risk Assessment Document) for the Employer (or business owner), in the buildings where people work.

\subsection{Physical Risk}

The so-called microclimate also falls within the perimeter of "physical risk", subject to the assessment of business risks as described in Article 180 (Title VIII, Chapter I) of the Legislative Decree of 9 April 2008, n. 81 (Consolidated text on health and safety at work - Italy). Often, especially in the past, the uncomfortable situations within the workplace related to microclimatic conditions (e.g. Levels of temperature, humidity, currents and air jolts), have been underestimated; in reality the resulting inconveniences can have a significant impact on both the physical health and the psychological well-being of the workers, with nonnegligible repercussions on the company economy if they are then reflected, as it can happen, in days of absence or illness.

Going into the specifics of the legislation, Annex IV in point 1.9 defines the minimum requirements that workplaces must possess in order to be compliant and therefore ensure adequate conditions of well-being. The first aspect evaluated is the one related to the "ventilation of closed workplaces", which must always be guaranteed preferably by opening windows and, if not possible, with "periodically controlled and maintained ventilation systems", in order not to expose workers to the direct air draft.

Another important aspect that should not be underestimated is the "correct regulation of the temperature", which must be adequate considering the type of work and the physical efforts required. There is therefore no precise indication of the temperature to be set, which varies precisely taking into account the specific activities and which must also be regulated according to the external ambient temperatures, avoiding rapid and excessive changes. Finally, the degree of humidity also plays an important role, it must always be kept under control and kept within adequate levels, compatible with the technical needs of the work. 
According to the legislation in Italy, any risks from exposure to uncomfortable temperatures are mainly of a physical nature, although it is important not to underestimate some psychological aspects. Heavy thermal stress, as well as prolonged exposure to inadequate temperatures or direct air currents, can cause physical discomfort in the respiratory system, skeletal muscle, gastrointestinal tract, in extreme cases leading to heat or cold strokes with serious consequences on the whole organism.

Physical agents represent factors, governed by physical laws, which cause a transformation of the environmental conditions in which they occur. Their presence determines an input of energy, in the living and working environments, which, beyond the tolerated values, is potentially harmful to human health.

The "physical risks" contemplated in the Legislative Decree n.81 concern: noise, mechanical vibrations, electromagnetic fields, optical radiation of artificial origin, "microclimate", infrasound, ultrasound and hyperbaric atmospheres.

Table I - Physical risks for humans, including microclimatic risk, in working places as "originally" indicated in the publication "La valutazione del microclima" edited by Inail ISBN 978-88-7484-114-1

\begin{tabular}{|c|c|}
\hline Agenti fisici & Riferimenti legislativi \\
\hline Rumore & $\begin{array}{c}\text { d.Igs. } 81 / 08 \text { e s.m.l. } \\
\text { (Titolo VIII, Capo I; Titolo VIII, Capo II) }\end{array}$ \\
\hline Vibrazioni & $\begin{array}{l}\text { d.Igs. } 81 / 08 \text { e s.m.l. } \\
\text { (Titolo VIII, Capo I; Titolo VIII, Capo III) }\end{array}$ \\
\hline Campi elettromagnetici & $\begin{array}{l}\text { d.Igs. } 81 / 08 \text { e s.m.i. } \\
\text { (Titolo VIII, Capo I; Titolo VIII, Capo IV) }\end{array}$ \\
\hline Radiazioni ottiche artificiali & $\begin{array}{l}\text { d.lgs. } 81 / 08 \text { e s.m.i. } \\
\text { (Titolo VIII, Capo I; Titolo VIII, Capo V) }\end{array}$ \\
\hline Radiazioni Ionizzanti & d.lgs. 230 del 17 marzo 1995 e s.m.i. \\
\hline Microclima & d.Igs. $81 / 08$ e s.m.I. (Titolo VIII, Capo I) \\
\hline Infrasuoni, Ultrasuoni & d.Igs. 81/08 e s.m.l. (Titolo VIII, Capo I) \\
\hline Atmosfere iperbariche & d.Igs. 81/08 e s.m.i. (Titolo VIII, Capo I) \\
\hline
\end{tabular}

The Legislative Decree n. 81 describes the microclimate as one of the "physical risk" agents. The principle stated in general in art.28 and reiterated in relation to physical agents in art. 181 "obliges the Employer to assess all risks to health and safety, including therefore also those due to exposure to microclimates of workers", in relation to which there is therefore an obligation (punishable) to "assess and identify the preventive and protective measures to minimize the risk".

The technical standard UNI EN ISO 7730 is, to date, the key document for the evaluation of thermo-hygrometric comfort. It provides a criterion for quantifying distress based on an index called PMV, acronym for Predicted Mean Vote (predicted average vote) which represents the best summary of the provisions of Annex IV: it integrates the physical quantities mentioned (temperature, humidity, irradiation solar energy, air movement) with the subjective indicators relating to the clothing and metabolic expenditure of the subject (working methods applied and physical efforts imposed). 
The advantage of the PMV method is that, based on strictly physiological considerations and having been validated on a significant sample of subjects, it re-proposes on objective grounds a feeling of satisfaction which by its very nature is intrinsically subjective. In fact, the procedure is based on the existence of a two-way relationship between the energy balance of the human body, and thermal sensation, with associated comfort or discomfort. In the case of the evaluation of moderate environments such as offices or in general indoor working places), the indices used, according to the UNI EN ISO 7730:2006 standard, are the Predicted Mean Value (PMV) and the Predicted Percentage of Dissatisfied (PPD). The PMV value is expressed by the following Mr.Fanger equation:

$$
\mathrm{PMV}=\mathrm{CT}\left(0,303 \cdot \mathrm{e}^{-0,036 \mathrm{M}}+0,028\right)
$$

where CT represents the thermal load determined by the difference between the thermal power transferred by an individual to the environment and that exchanged by the same in homeothermic conditions; the value of $\mathrm{M}$ in the exponent expresses the metabolic expenditure of the organism. The value of the PMV index expresses the deviation of the real situation of the thermal environment compared to that of well-being (also called comfort, i.e. "the mental condition in which satisfaction for the thermal environment is expressed") and represents different levels of acceptability of a given thermal environment.

Table II - Correspondence between the thermal sensation and PMV according to ASHRAE 7 points scale

\begin{tabular}{|c|l|}
\hline+3 & Hot \\
\hline+2 & Warm \\
\hline+1 & Slightly warm \\
\hline 0 & Neutral \\
\hline-1 & Slightly cool \\
\hline-2 & Cool \\
\hline-3 & Cold \\
\hline
\end{tabular}

Table III - Distribution of the individual response in correspondence with different values of PMV (UNI EN ISO 7730)

\begin{tabular}{|c|c|c|c|c|}
\hline \multirow{2}{*}{ PMV } & PPD & \multicolumn{4}{|c|}{ Persons predicted to vote a } \\
& & 0 & $-1,0$ or +1 & $-2,-1,0,+1$ or +2 \\
\cline { 3 - 5 } & & 5 & 25 & 70 \\
\hline+2 & 75 & 30 & 75 & 95 \\
+1 & 25 & 55 & 90 & 98 \\
$+0,5$ & 10 & 60 & 95 & 100 \\
0 & 5 & 55 & 90 & 98 \\
$-0,5$ & 10 & 30 & 75 & 95 \\
-1 & 25 & 5 & 25 & 70 \\
-2 & 75 & \multicolumn{3}{|l}{} \\
\hline a & Based on experiments involving 1300 subjects.
\end{tabular}

Table III illustrates the distribution of individual responses, quantified by the thermal sensation expressed in the ASHRAE 7-point Table II scale as a function of the PMV. The table 
clearly illustrates that thermal well-being is a subjective sensation widely but not universally shared: even for PMV values that identify an overall sensation of hot / cold (PMV = \pm 1 ), a not small fraction of subjects $(30 \%)$ expresses a neutral judgment. Vice versa for PMV = $0,35 \%$ of subjects express a vote of \pm 1 thus declaring a sensation of slight warm / cold.

The predictable percentage of dissatisfied is related to the PMV value from the equation:

$$
\mathrm{PPD}=100-95 \times \exp -\left(0,03353 \times \mathrm{PMV}^{4}+0,2179 \times \mathrm{PMV}^{2}\right)
$$

and the graphical representation is expressed in Figure 4. In conditions of PMV $=0$ the value of the PPD is equal to 5\%: this means that even in optimal conditions there is a percentage of subjects who consider the microclimatic conditions unsatisfactory.

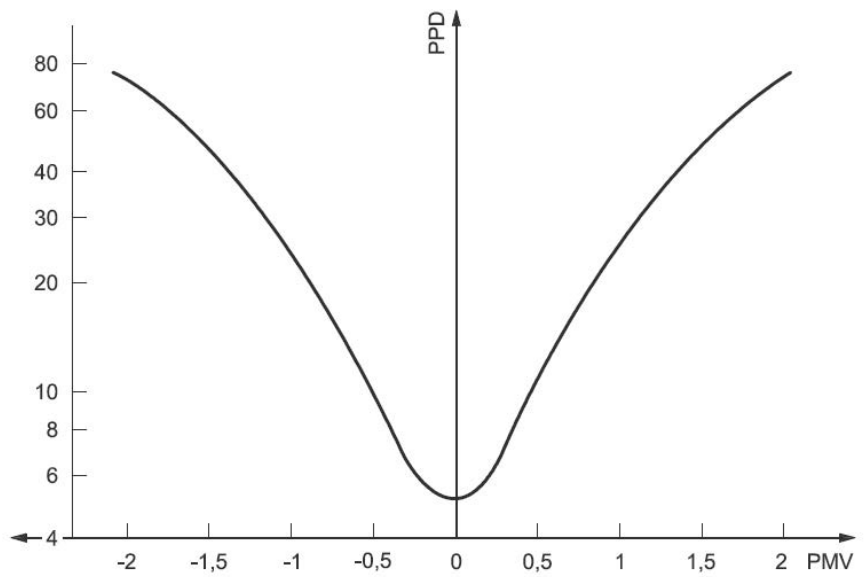

Fig. 4: Diagram of predicted percentage of dissatisfied PPD in operation of the expected average grade (PMV) (UNI EN ISO 7730)

In any case, the judgment on environmental well-being expressed by the PMV is considered realistic when the PMV index remains within the limits -2 and +2 .

In the specific case of climatization, air conditioning and ventilation systems, in a context of work environments inside nZEB buildings, with high and very high energy efficiency, it is extremely important to highlight that the thermal loads can be greatly influenced by several aspects independent form the HVAC systems, such as the degrees of crowding of the spaces and the free energy gains (such as: solar gains through windows, machinery and information technology heat, etc.). 


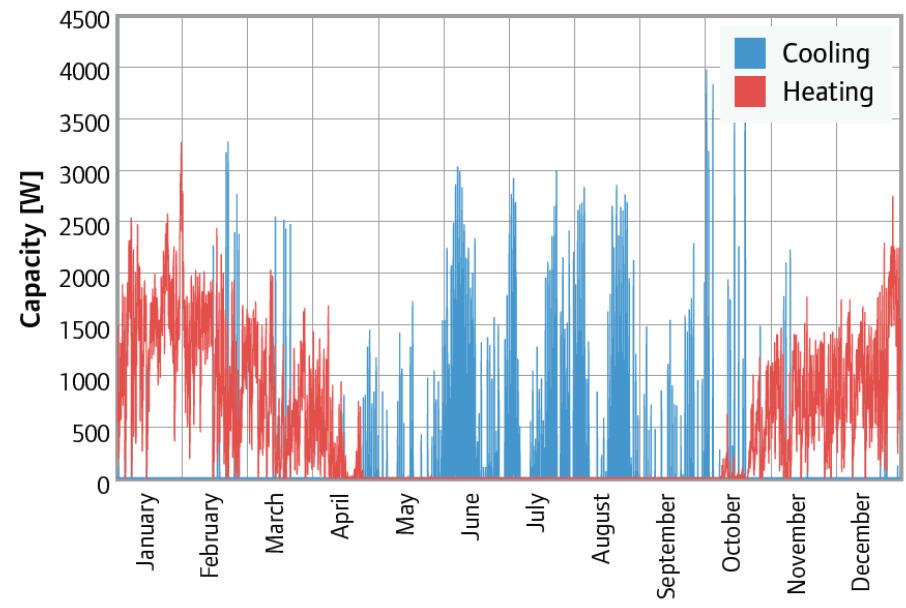

Fig.5 - Cooling loads, in modern highly insulated envelop buildings, are present in summertime as well as throughout the intermediate seasons (spring / autumn). Source: Publication Heating and cooling challenge in nZEB of REHVA - Federation of European Heating, Ventilation and Air Conditioning.

In this type of energy efficient buildings, now mandatory by law, the need for new and more sophisticated control systems is beginning to be relevant, they must be able to predict the needs in terms of heating, cooling and air renewal and to regulate them in a timely and precise manner. The non-correct, or timely proper, management of these variables, can generate "physical risks" to the health of workers with greater frequency and probability.

\subsection{Chemical Risk}

The "chemical risk" within the workplace is much more widespread than one might think at a first assessment; unlike what is believed, in fact, not only the chemical industries or refineries, or research and synthesis laboratories are concerned, but a wider range of work activities. In fact, starting from the following definition of chemical agent, as derived from Article 222 of Legislative Decree 81/08 "all elements or chemical compounds, whether alone or in their mixtures, in their natural state or obtained, used or disposed of, including disposal as waste, through any work activity, whether they are produced intentionally or not and are placed on the market or not" it is easy to understand how chemical agents are in themselves part of our daily existence: from cleaning products and disinfection to those for printing or for food preservation. Such a high presence of chemical substances, even potentially dangerous ones, involves a spread of chemical risk in the workplace and a corresponding relevant number of workers exposed, at times, in a completely unintentional way. As a result of this diffusion, a univocal classification system of chemical agents has long been necessary, which provides for a first macro-distinction into two classes:

A - agents with chemical-physical hazardous properties, defined: flammable, explosive, oxidizing and corrosive agents;

$\mathrm{B}$ - agents with toxicological properties, further distinguished into harmful, sensitizing, irritating, toxic, teratogenic and carcinogenic substances.

If generally accidental and inadequately controlled exposure to agents of the first class generates an injury, exposure to agents of the second class generates an occupational disease. 
In the specific case of climatization, air conditioning and ventilation systems, lack of maintenance can set off a "chemical risk" when, for instance, the materials that make up the insulation of the ducts come into contact with water or other substances, generating other by-products which, if inhaled, can be harmful to the human occupants of the working indoor places.
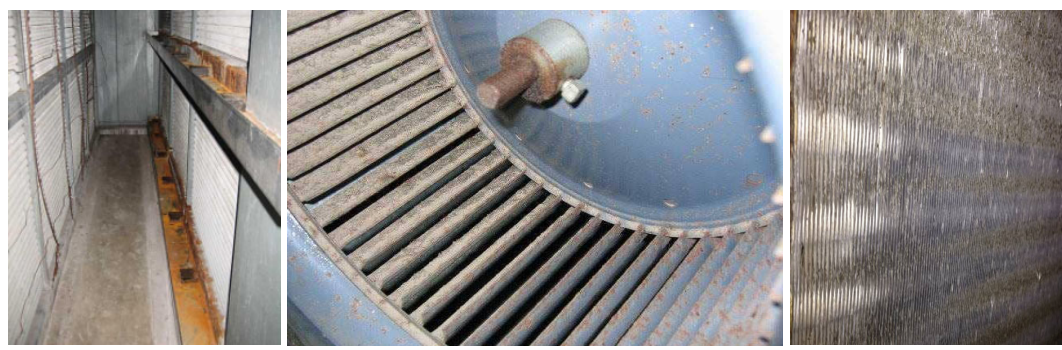

Fig.6 - Evident state of degradation with the generation of products, from oxidation and corrosion of metals and / or insulation materials, which combined with condensed water or humid air can in turn give rise to chemical substances that can be harmful to inhalation by people

\subsection{Biological Risk}

The biological risk that we analyse in this report is the possibility of contracting an infectious disease during work activities involving exposure to biological agents. The reference standards define Biological Agent "any microorganism even if genetically modified, cell culture and human endoparasite that could cause infections, allergies or intoxications", in general defined as:

- INFECTIONS: The invasion by any type of microorganism of the body's sterile tissues, which are not effectively hindered by immune defenses, laying the foundations for the development of an infectious disease;

- ALLERGIES: It is an abnormal and specific reaction of the organism that occurs in the event of contact with foreign entities (allergenic), which in most people, as a rule, do not generate disturbances;

- POISONING: Pathological state due to the action of substances / agents that are toxic to the body.

From a "biological risk" point of view, it cannot be excluded that inadequate management of climatization, air conditioning and ventilation systems and/or inaccurate maintenance, may favour bacterial proliferation in systems, especially if associated with high humidity levels, with possible biological repercussions (e.g. cases of contamination by legionella).

Biological agents can be bacteria (e.g. salmonellae causing typhus, tuberculosis mycobacterium), viruses (e.g. hepatitis, influenza, AIDS and more recently SARS-CoV-2 viruses), fungi (e.g. fungi that cause candidiasis or aspergillosis), microorganisms formed by multiple cells (e.g. scabies mites or some intestinal parasites) which, in relation to the examples mentioned above can infect humans.

For the identification of the "Biological risk", the legislation divides microorganisms into 4 classes of increasing danger, based on the corresponding characteristics of the biological agent of:

- INFECTIVITY: the ability of a microorganism to penetrate and multiply within a host; 
- PATHOGENICITY: the ability of a microorganism to produce disease as a result of infection;

- NEUTRABILIZABILITY: the availability of effective prophylactic measures designed to prevent the disease, or effective therapeutic treatments for the treatment of the disease itself;

- TRANSMISSIBILITY: the ability of a microorganism to be transmitted from an infected organism to a susceptible one. The transmission path of a given agent can be single or multiple.

\subsubsection{Special focus on SARS-CoV-2}

The SARS-CoV-2 pandemic that occurred in 2020 highlighted evident gaps and weaknesses that in every country made it impossible to stem, or at least limit, the uncontrolled development of this epidemic which, in a short time, has become pandemic.

Ventilation systems are undoubtedly among the most important tools for reducing the risk of contagion from airborne pathogens in confined spaces. "Airborne contamination" and "ventilation systems" were two widely debated topics during the first months of the pandemic: at the beginning, when knowledge was still limited, it was believed that SARSCoV-2 spread mainly through surface contamination by unknowingly infected individuals. Over time it has emerged instead that it is a virus that is transmitted mainly by air, through the drops of saliva that we emit speaking (droplet) and through the even smaller ones of water vapor that we emit while breathing and which remain for a long time suspended in the air (aerosol).

It is worth remembering that initially, in fact, the mode of contagion by transmission by airborne aerosol was excluded but, despite this, HVAC systems were indicated as an amplifier of the risk of contagion in closed environments. Exemplary was the "famous" case of the "Guangzhou restaurant" where the air conditioning system had been indicated as responsible for the spread of the virus inside the restaurant, even if the authors of that article had clearly written that between the recommendations to reduce the risk of contagion one of the necessary interventions would have been to improve the ventilation of the room.

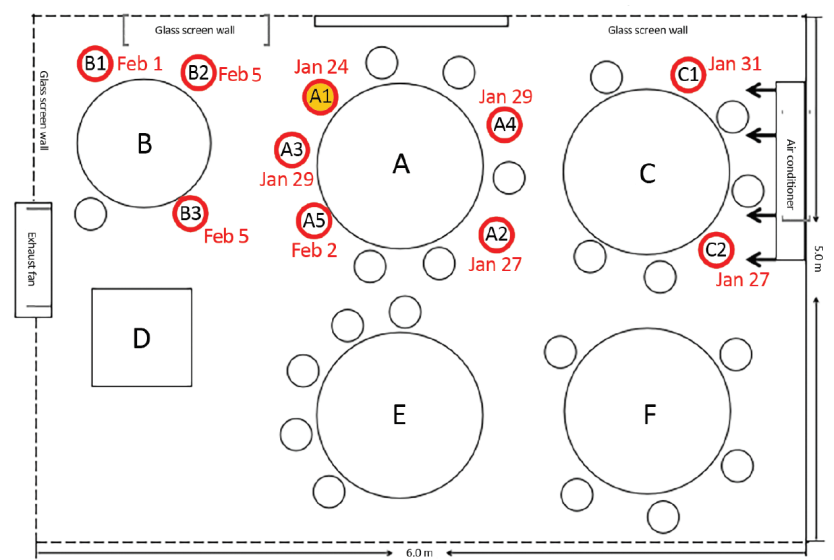

Fig.7: Research "COVID-19 Outbreak Associated with Air Conditioning in Restaurant, Guangzhou, China, 2020": Sketch showing arrangement of restaurant tables and air conditioning airflow at site of outbreak of 2019 novel coronavirus disease, Guangzhou, China, 2020. Red circles indicate seating of future case-patients; yellow-filled red circle indicates index case-patient. 
Nowadays, the importance and role of ventilation systems have been reassessed, it has been understood that reducing the risk of contagion is a process that involves various measures both on a personal and institutional level and that, if appropriate and well designed, used and maintained, ventilation systems can play a fundamental role in the removal of airborne bio-contaminants inside closed environments and limit the "Biological Risk".

Actually, concerning SARS-CoV-2 for example, the head of health prevention department of the Italian Ministry of Health, with the letter dated April $29^{\text {th }} 2020$, has defined that for the Employer, it will be necessary to adopt a series of actions that will integrate the DVR (Documento di Valutazione dei Rischi), designed to prevent the risk of SARS-CoV-2 infection in the workplace, also contributing to the prevention of the spread of the pandemic.

For this reason, biological risk and the role connected to climatization, air conditioning and ventilation systems should fully enter into the implementation of the DVR as a formal legislative duty for Employers, in order to prevent and protect workers from diseases. In fact on the occasion of the SARS-CoV-2 pandemic, many Chief Security Officers have been forced to carry out appropriate risk assessments and to take countermeasures in their company's DVR.

Actually, the SARS-COV-2 is listed in Annex XLVI of Legislative Decree no. 81/2008 and it is classified in group 2.

For all these reasons a growing attention have been devoted on the application of several countermeasures in HVAC (e.g. the document "Protocollo per la riduzione del rischio da diffusione del SARS-CoV-2 nelle operazioni di gestione e manutenzione degli impianti di climatizzazione e ventilazione esistenti" edited by AiCARR, July 2020 - Italian Association of Air Conditioning, Heating \& Refrigeration) such as the use and proper maintenance of several types of: mechanical filters (including HEPA) normed by the UNI EN ISO 16890:2017, electronic filters normed by the UNI 11254:2007 and several other air sanitation and disinfection techniques as listed by ASHRAE on the official website (e.g. https://www.ashrae.org/technical-resources/filtration-disinfection) not yet completely normed and still under test by several manufacturers.

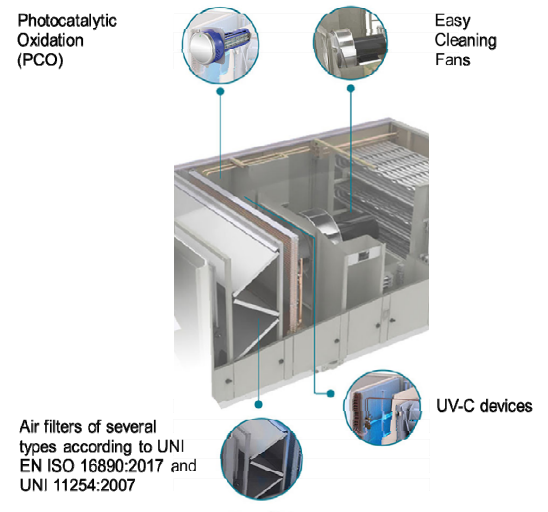

Fig.8: Illustrative not exhaustive picture of some technologies aimed to decrease the biological risk of SARS-COV-2 in air handling units and air HVAC systems in general.

\subsubsection{Special focus on Legionella}

Among the pathogenic bacteria, the possible presence of Legionella, a gram-negative aerobic bacillus, ubiquitous in natural aquatic ecosystems, is particularly relevant. If Legionella 
finds favourable conditions for its survival, it is able to pass from natural to artificial environments, reaching growth peaks at temperatures between 28 and $50^{\circ} \mathrm{C}$. The frequency of infection and the real pathogenicity of Legionella and different serogroups is not well known not only for the actual diagnostic difficulty, but also for the lack of identification of the species and serogroups less frequently related to the reported pathologies. In an aeraulic system, the areas at risk of Legionella contamination are those in which water is present, in particular the humidification sections, the condensate drain siphons, for example, inside the water treatment units. Air (AHU) and cooling towers.

Annex XLVI of Legislative Decree 8 April 2008, no. 81 classifies legionella as a biological agent of group 2 which, in turn, art. 268, paragraph 1, letter b, defines as "an agent who can cause disease in human subjects and constitute a risk for workers; it is unlikely to spread to the community; effective prophylactic or therapeutic measures are usually available ". The Employer is obliged (Article 271, Legislative Decree No. 81/2008) to: assess the risk of this pathogen by drawing up the related assessment document (Article 17, paragraph 1), apply the principles of good microbiological practices and to adopt, in relation to the ascertained risks, protective and preventive measures adapting them to the particularities of the working situations.

\section{Consolidated text on health and safety at work: Legislative Decree 81/2008 annex IV, requirements for workplaces}

Beyond the advantage in terms of indoor air quality and the importance and obligations of keeping ventilation systems clean and efficient, there is not always a well-defined maintenance and risk assessment plan for these systems. For this reason it is correct to address the issue from the point of view of the "physical, chemical and biological risks" to which the occupants of the workplaces within the buildings are subjected and focusing, in particular, on those areas of the spaces used for workers that are fully regulated by Legislative Decree 9 April 2008, n. 81: Consolidated text on health and safety at work, implementation of article 1 of law no. 123 on the protection of health and safety in the workplace, including the specific Risk Assessment of microclimate conditions.

Article 64 of Legislative Decree 81/2008, in non-residential buildings, obliges the Employer to provide for the regular maintenance and cleaning of ventilation systems and, specifically, Annex IV: "Requirements for workplaces" provides very precise indications regarding the characteristics of the systems, cleaning and maintenance, highlighting, in section "1.9 Microclimate" chapter "1.9.1. Ventilation of closed workplaces "to the following points:

1.9.1.1. In closed workplaces, it is necessary to ensure that taking into account the working methods and physical efforts to which the workers are subjected, they have healthy air in sufficient quantity, also obtained with ventilation systems;

1.9.1.2. If an aeration system is used, it must always be kept functional. Any failure must be signalled by a control system when this is necessary to safeguard the health of the workers;

1.9.1.3. If air conditioning or mechanical ventilation systems are used, they must function so that workers are not exposed to disturbing drafts;

1.9.1.4. The same systems must be periodically subjected to checks, maintenance, cleaning and sanitization to protect the health of workers;

1.9.1.5. Any sediment or dirt that could pose an immediate danger to the health of workers due to the pollution of the air they breathe must be eliminated quickly.

All these elements are a clear indication of how much the ventilation systems must be maintained and correctly managed in order to minimize the "physical, chemical and biological" risks. 
It is also evident the need for those Employers who use in the company systems equipped with components such as: Air Handling Units, Fan-Coils, Splitted Air Conditioners, Air Ducts, Air Diffusers, Air Intake Grilles, Filters, etc. to carry out a specific risk analysis and to prepare the DVR (Documento di Valutazione dei Rischi - Risk Assessment Document) for the buildings where people work.

\subsection{The general risk assessment process}

A fundamental tool to reduce the risk and consequent management of the same, through the adoption of preventive measures, remains the detailed assessment of the "critical points" of the plants by means of a Risk Assessment Document (DVR) whose realization can be carried out trough the following 7 main stages:

- Perform a careful analysis of the work process;

- Identify the dangers and any critical issues;

- Consider the damage and its potential severity;

- Detect and take into account near-accidents;

- Provide and implement the necessary prevention and protection measures;

- Evaluate all risks;

- Monitor that the expected results are in place

With the term "risk" we mean the probability of reaching the potential level of damage in the conditions of use or exposure to a specific factor or agent, or to their combination and is evaluated by applying the following formula:

$$
\mathrm{R}=\mathrm{P} \times \mathrm{D}
$$

Where:

$\mathrm{R}=\mathrm{RISK}$;

$\mathrm{P}=$ PROBABILITY defined as the measure by which it is judged that the accident may occur. It essentially represents a more or less direct correlation between the objective state of technical-regulatory compliance of the material elements involved and the hypothesized damage. To qualify it, 4 Levels are defined:

1 - Improbable;

2 - Not much probable;

3 - Probable;

4 - Very probable.

$\mathrm{D}=$ ENTITY OF DAMAGE defined as the consequence of the manifestation of a danger that can harm both things and people and whose effect can be immediate (injury) or delayed over time (occupational disease). To qualify it, 4 Levels are defined:

1 - Low;

2 - Medium;

3 - Serious;

4 - Very probable.

Using the formula $\mathrm{R}=\mathrm{P} \times \mathrm{D}$ it is possible to realize a matrix of the different risks, in order to prepare the DVR that must contain:

- All risks are processed in collaboration with the RSPP (Responsabile del servizio di prevenzione e protezione - Responsible for the prevention and protection service), the MC (Medico Competente - Competent Doctor) and with the consultation of the RSL (Rappresentante dei Lavoratori per la Sicurezza - Workers Safety Representative); 
- The risk assessment must be revised immediately in occasion of any changes to machinery, production process or work organization significant for the health and safety of workers or when the results of health surveillance highlight the need. The document must be updated within 30 days from any changes;

- The document must have a clear date of issue and must be kept filed at the company headquarters.

\subsection{General evaluations for the HVAC systems}

With regard to the preparation of the DVR related to air systems, it is possible and advisable to support the formal activities of the company's safety managers with the specialistic professional contribution of an A.S.C.S. (Air System Cleaning Specialist - Specialist in the sanitization of aeraulic systems) as, for example, indicated by A.I.I.S.A., the Italian Association of Aeraulic Systems Hygienists, in the document "Protocol for the inspection and sanitization of aeraulic systems" (Protocollo per l'ispezione e la sanificazione degli impianti aeraulici), as these professionals are workers/managers who possess the needed knowledge to collect and process the information relevant to the various phases in order to evaluate the best corrective actions to be implemented.

In this regard, A.I.I.S.A. recommends a specific analysis and intervention process, not only aimed at identifying risks but also keeping care about operator safety and at the same time resolving critical issues through the following 8 steps:

1. TECHNICAL OVERVIEW OF THE COMPLETE AIR SYSTEM

2. TECHNICAL DETAILED INSPECTION

3. TECHNICAL INSPECTION REPORT

4. PROJECT OF RESOLUTION OF THE CRITIC POINTS AND RISKS

5. BONIFICATION OF THE AERAULIC SYSTEM

6. POST-REMEDIATION TECHNICAL INSPECTION

7. POST-REMEDIATION INSPECTION TECHNICAL REPORT

8. CONTROL PLAN: VISUAL INSPECTION AND PERIODIC SURVEILLANCE TECHNIQUE

A.I.I.S.A. recommends that the 8 steps must be conducted in the order shown, as each of them is preparatory to the next one. In each of these phases, in fact, fundamental information is collected for the correct success of the phase that has yet to be implemented and allows the identification of critical points as required for the preparation of the DVR.

The identification of the aforementioned critical points and the carrying out of periodic water / dust samples represents an indispensable first step for the assessment of the related biological risks and the development of a detailed monitoring and prevention program as well as of the DVR.

\subsection{Operating procedure for the evaluation and management of risks related to the hygiene of air handling systems}

Another very important procedure that can support the Employer with practical indications for the assessment and management of risks related to the hygiene of air handling systems and for the planning of maintenance interventions, in consideration of what is reported in the Regional Laws, Italian National Guidelines and technical standards produced on the subject is certainly the document "Procedura operativa per la valutazione e gestione dei rischi correlati all'igiene degli impianti di trattamento aria" edited in Italy with the Accordo Conferenza Stato-Regioni 07.02.2013, where all phases are clearly described. 


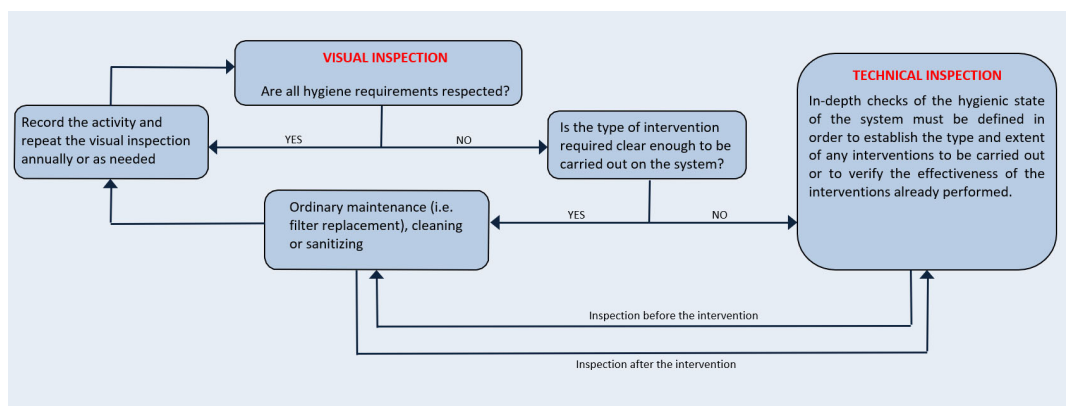

Fig.9: Flow chart of the operative procedure "Procedura operativa per la valutazione e gestione dei rischi correlati all'igiene degli impianti di trattamento aria" edited in Italy with the Accordo Conferenza Stato-Regioni 07.02.2013”

\section{The relevant importance of proper maintenance}

Aeraulic systems are used to control the thermo-hygrometric conditions of living and working environments, to ensure adequate air exchange and to reduce the concentrations of dust and other airborne particles; however, if they are not properly managed and maintained, they can spread pollutants of various kinds into the environment: pathogenic microorganisms, allergens, dust, fibres and chemical agents.

Therefore, the plant can become a source of risk (physical, chemical and biological) for the occupants and for the technicians involved in any maintenance and cleaning operations. To keep the systems clean and in a good state of conservation, it is necessary to check them regularly to ascertain their hygienic state, to maintain them and, if necessary, to sanitize them.

When it comes to maintenance, the Standard UNI 9910 (Terminology) defines maintenance as: "the combination of all actions, technical and administrative, including supervisory actions, aimed at maintaining or restoring an entity to a state in which can perform the required function". Italian law 109/1994 is also inspired by this definition, specifying that the work must be maintained or brought back in the condition to perform the function "provided for in the provision of approval of the project".

From these definitions it could be deduced that the maintenance of the systems is almost exclusively linked to making the parts of the system work overtime, as conceived and designed from a technical/mechanical point of view. In practice it is simply a question of avoiding that any states of "failure" of individual components prolonged over time, can create a "failure", that is, a permanent event. In reality, this is not the only way to understand good and correct maintenance of plants. 


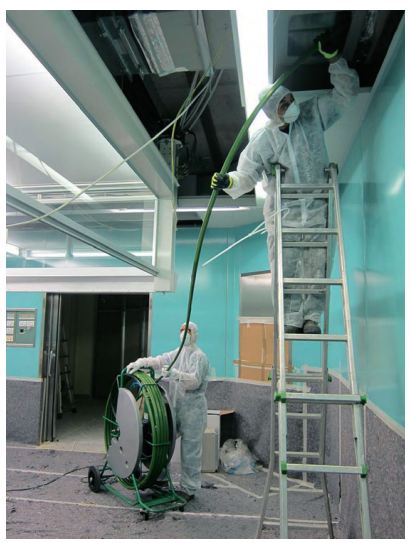

Fig.10: Illustrative picture of professional activity of air ducts inspection and cleaning from the publication "Impianti di climatizzazione: salute e sicurezza nelle attività di ispezione e bonifica" edited by Inail

Climatization, air conditioning and ventilation systems not only perform functions related to maintaining a certain environmental thermal "comfort", but also to ensure indoor air quality in line with the health and safety laws for the protection of the occupants. It is not uncommon for any maintenance problems to arise from errors in the initial conception of the system right from the design stages and therefore it becomes very problematic, if not impossible, to intervene on the aeraulic systems already installed.

For these reasons, for the purposes of good maintenance, it is necessary to design, build and install the aeraulic systems always keeping in mind the maintenance needs. All components (including but not limited to: Air Handling Units, Fan-Coils, Splitted Air Conditioners, Air Ducts, Air Diffusers, Air Intake Grilles, including Filters, etc.) that are used in a climatization, air conditioning and ventilation system, must not represent, due to lack of maintenance and cleaning/hygiene of the ventilation systems, a risk to the health of people present in confined spaces, whether they are residential or work, public and private buildings.

The risk in these cases, in fact, is represented by the possible accumulation of "dirt" on all or part of the aeraulic surfaces (horizontal and vertical) that can develop bacterial cultures, fungi or other types and possibly pathogenic and / or not pathogenic. Dust deposits can in fact contain various organic substances, which were already present in the air and then settling, thanks to the stable internal conditions, humidity, darkness and the presence of nutrients, can develop and colonize the inside of the plant itself.

\subsection{Influence on cleaning and sanitization possibilities of the internal surfaces of air ducts due to complexity of the ductworks in centralized and decentralized systems}

Ductworks can represent, if not properly maintained, a very critical point of accumulation of dust and other substances, because, in particular with centralized ventilation systems, the possibility to have long and very articulated air duct network, not always permit an easy access and cleaning of the internal surfaces of the air duct network. 

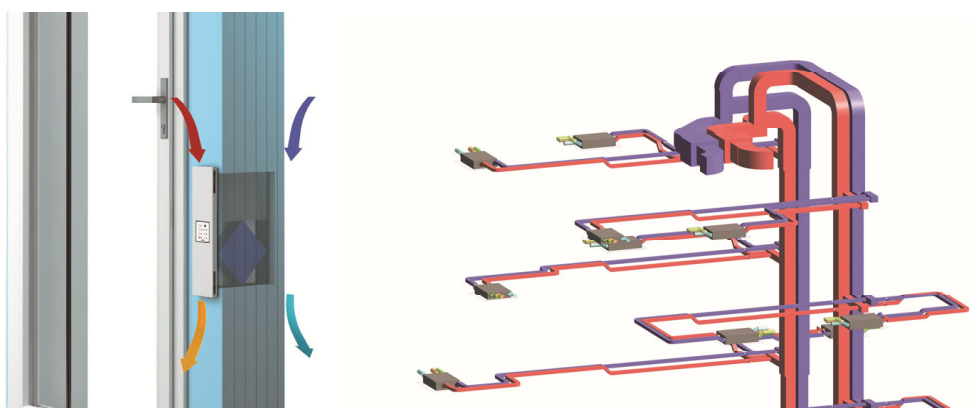

Fig.11: The picture on the left shows a decentralized solution for fresh air renewal and purification that requires very limited air ductworks, both in terms of extension and dimension, because every ambient, where humans are, have one or more individual dual-flow ventilation units. The picture on the right shows how a centralized ductwork system can be very extended and could represent a higher internal ducts surface that can involve higher levels of risks when it comes to assure correct cleaning and hygiene of an extended ductwork

In this field some decentralized systems of air renewal and purification can be an advantage, because the air duct surfaces are very limited compared to the decentralized systems and therefore any activity of cleaning and sanitization on ductworks can be easier and potentially with lower risks for occupants. In any case, for any specific evaluation of cleanliness of the ventilation systems, with particular reference to ducts, it is very important to take into consideration the UNI EN 15780:2011. This European Standard applies to both new and existing ventilation and air conditioning systems and specifies the assessment criteria of cleanliness and cleaning procedures of these systems. The validation of the effectiveness of cleaning applies also to products, which conform to EN 1505, EN 1506, EN 13053, EN 13180 and EN 13403, used in air conditioning and ventilation systems for human occupancy defined in the scope of CEN/TC 156. This European Standard specifies general requirements and procedures necessary in assessing and maintaining the cleanliness of ducted ventilation, including:

- cleanliness quality classification;

- how to assess the need for cleaning (visual, measurements);

- assessment frequency (general guidance);

- guidance of inspections in accordance with EN 15239 and EN 15240 when relevant;

- selection of cleaning method;

- to be in line with handing over documentation according to EN 12599;

- how to assess the result of cleaning.

\section{Conclusions}

A substantial growth in the usage of climatization, air conditioning and ventilation energy efficient systems is foreseen in the years to come as an indirect consequence on Energy Efficient Buildings, according to the orientation of the European Commission to the sustainable development as an indispensable element to guarantee economic prosperity and life quality for people, respecting the planet.

These systems can be used to control the thermo-hygrometric conditions of living and working environments, to ensure adequate air exchange and to reduce the concentrations of dust and other airborne particles, in order to generate the correct conditions of health and comfort for workers in buildings dedicated to work activities. 
The Italian Legislative Decree n. 81 defines "microclimate" as one of the "physical risk" agents. The principle stated in general in art.28 and reiterated in relation to physical agents in art. 181 "obliges the Employer to assess all risks to health and safety, including therefore also those due to exposure to microclimates of workers", in relation to which there is therefore an obligation (punishable) to "assess and identify the preventive and protective measures to minimize the risk".

Climatization, air conditioning and ventilation systems can be affected by this and the maintenance of these systems in order for them to be in a good state of conservation, clean, hygienic and efficient, requires a plan of regular checks to ascertain their hygienic state, maintain them and possibly sanitize them.

Through the duly and careful implementation of the DVR and any related activities regulated by the Legislative Decree of 9 April 2008, n. 81 it is possible, for climatization, air conditioning and ventilation systems, not only to fulfil legal obligations for the Employer but also to guarantee a healthy and constantly maintained work environment, with limited or close to zero risks for workers. 


\section{References}

1. European Parliament. Directive (EU) 2018/844 of the European Parliament and of the Council of 30 May 2018 amending Directive 2010/31/EU on the energy performance of buildings and Directive 2012/27/EU on energy efficiency (2018);

2. COM/2020/662: Communication from the commission to the European Parliament, the council, the European economic and social committee and the committee of the regions. A Renovation Wave for Europe - greening our buildings, creating jobs, improving lives; C(2020)6929: Commission Implementing Regulation (EU) of 14.10.2020 detailing the technical modalities for the effective implementation of an optional common Union scheme for rating the smart readiness of buildings (2020);

3. Review study on Regulations EU 1253/2014 (Ecodesign requirements for ventilation units) and EU 1254/2014 (Energy labelling of residential ventilation units) of the European Commission (2020);

4. Lars Sønderby Nielsen M.Sc. (Eng). 2011. Heating and cooling challenge in nZEB REHVA Journal - May 2011, 41-46 (2011);

5. Author affiliations: Guangzhou Center for Disease Control and Prevention, Guangzhou, China (J. Lu, K. Li, C. Xu, W. Su, C. Yu, Z. Yang); Guangzhou Yuexiu District Center for Disease Control and Prevention, Guangzhou, China (J. Gu, Z. Lai, D. Zhou, B. Xu). 2020. Research "COVID-19 Outbreak Associated with Air Conditioning in Restaurant, Guangzhou, China, 2020” (2020);

6. CEN/TC 156 Bruxelles: European Committee for Standardization - Ventilation for buildings: standardization of terminology, testing and rating methods, dimensioning and fitness for purpose of natural and mechanical ventilation systems and components for buildings subject to human occupancy;

7. Italian Legislative Decree of 9 April 2008, n. 81: Consolidated text on health and safety at work, implementation of article 1 of the law of 3 August 2007, no. 123 regarding the protection of health and safety in the workplace (2008);

8. Italian agreement between the Ministery of Healt and the Italian regions: «Linee-guida per la tutela e la promozione della salute negli ambienti confinati». Gazzetta Ufficiale 276 del 27.09.2001 (2001);

9. Italian agreement between the Government and the Italian regions: «Accordo, ai sensi dell'articolo 4 del decreto legislativo 28 agosto 1997, n. 281, tra il Governo, le Regioni e le Province Autonome di Trento e di Bolzano sul documento recante: Linee guida per la definizione di protocolli tecnici di manutenzione predittiva sugli impianti di climatizzazione». Gazzetta Ufficiale 256 del 3.11.2006 (2006);

10. Italian guidelines issued by the Presidenza del Consiglio (Conferenza Permanente StatoRegioni) "Procedura operativa per la valutazione e gestione dei rischi correlati all'igiene degli impianti di trattamento aria" del 7 febbraio 2013 (2013);

11. UNI EN 15780:2011 Ventilation for buildings - Ductwork - Cleanliness of ventilation systems (2011);

12. Document "La valutazione del microclima" by Inail ISBN 978-88-7484-114-1 (2017). 


\section{Acknowledgments}

Special thanks go to A.I.I.S.A. the Italian Association of Aeraulic Systems Hygienists for having shared the passion for the hygiene and quality of aeraulic systems testified by the document "Protocollo per l'ispezione e la sanificazione degli impianti aeraulici" rev. 0.1 of April $30^{\text {th }} 2018$, that was extremely important in the realization of chapter 4.2.

Special thanks also go to Air Control S.r.l. for having shared with us the laboratory test results done in cooperation with the University of Milano (Department of biomedical and clinics sciences "Luigi Sacco") and with the Eurofins Biotech-Germande laboratory, according to EN 17272 on the specific Evaluation of Virucidal Activity, performed on Photocatalytic Oxidation (PCO) applications in HVAC and Helty S.r.l. for the support in describing the value of decentralized air renewal and purification systems and the potential impact they have in reducing, where possible, the ductwork extension and internal surfaces, and consequently decreasing the risk of dust accumulation in quantity and extension, themes that inspired the editing of chapter 5.1 of the present research.

Along with all other contributions, I would like also to thank Signify Italy S.p.A. as they have shared a number of valuable studies, laboratory tests and researches on UV-C technologies and in particular the extremely valuable research on the UV-C effects on SARSCOV-2, titled "A Critical Review on Ultraviolet Disinfection Systems against COVID-19 Outbreak: Applicability, Validation, and Safety Considerations" ACS Publications - Washington, DC that was helpful in the chapter 3.3.1 (Special focus on SARS-CoV-2) definition. 